\title{
O CURSO DE DIREITO INTERNACIONAL DOS CONFLITOS ARMADOS E A UTILIZAÇÃO DA EDUCAÇÃO A DISTÂNCIA: A VISÃO DOS SEUS DISCENTES
}

\author{
THE COURSE ON INTERNATIONAL LAW OF ARMED CONFLICTS AND THE USE \\ OF DISTANCE EDUCATIONE-LEARNING: THE VIEW OF ITS STUDENT BODY
}

\author{
Hercules Guimarães Honorato ${ }^{1}$ \\ ${ }^{1}$ Escola Superior de Guerra, Departamento de Ensino, Brasil, e-mail: hghhhma@gmail.com
}

\author{
ARTICLE INFO \\ Article history: \\ Received 2020-04-02 \\ Accepted 2020-06-20 \\ Available online 2020-06-20
}

Palavras-chave: Avaliação de curso. Curso de Direito Internacional dos Conflitos Armados. Educação a Distância. Ferramentas da plataforma Moodle. Processo de ensino e aprendizagem.

Keywords: Course evaluation. Course on International Law of Armed Conflict. E-learning. Moodle platform tools. Teaching and learning process.

RESUMO. O objetivo deste estudo é apresentar as contribuições da utilização de ferramentas da plataforma Moodle no Curso de Direito Internacional dos Conflitos Armados (CDICA), da Escola Superior de Guerra, segundo a visão dos seus alunos. Esta pesquisa é de abrangência qualitativa, com pesquisas documental e bibliográfica como técnicas exploratórias iniciais. A metodologia compreendeu ainda a aplicação de dois questionários com perguntas abertas aos sujeitos do estudo, 34 alunos, entre militares e civis, de diversas áreas de formação profissional. As coletas de dados foram disponibilizadas via survey online no Ambiente Virtual de Aprendizagem, ao final do curso e abrangeram os campos da gestão e ensino. Os resultados obtidos comprovaram que as expectativas dos alunos foram atendidas satisfatoriamente, e os estudos foram essenciais para subsidiar os desdobramentos que foram aprofundados na fase presencial posteriormente. Ao final, as seguintes contribuições foram apresentadas, a saber: (i) fórum de discussão aberto em ambas as fases do curso; (ii) aplicação e ampliação dos estudos de caso com exercícios de fixação; (iii) criação de uma pasta virtual com todo o material do curso e os estudos realizados pelos estagiários; (iv) possibilidade de especialização futura para os egressos do curso: (v) Plano de Ensino e Aprendizagem aperfeiçoados; e (vi) pré-teste de avaliação dos conhecimentos prévios dos estagiários.

ABSTRACT. The objective of this study is to present the contributions of the use of tools from the Moodle platform in the Course on International Law of Armed Conflict (CDICA), from the Escola Superior de Guerra, according to the students' view. This research has a qualitative scope, with documentary and bibliographic research as initial exploratory techniques. The methodology also included the application of two questionnaires with open questions to the study subjects, 34 students, among military and civilians, from different professional areas. The data collection was made available via online survey at the e-learning platform, at the end of the course, and covered the fields of management and teaching. The results obtained proved that the students' expectations were satisfactorily met, and the studies were essential to subsidize the unfolding's that were deepened in the face-to-face later phase. At the end, the following contributions were presented, namely: (i) open discussion forum in both phases of the course; (ii) application and expansion of case studies with memorization exercises; (iii) creation of a virtual folder with all the course material and studies carried out by the interns; (iv) possibility of future specialization for graduates of the course: (v) improved Teaching and Learning Plan; and (vi) pre-test to evaluate the interns' previous knowledge. 


\section{Introdução}

Ensinar e aprender, hoje, não se limita ao trabalho dentro da sala de aula. Implica em modificar o que fazemos dentro e fora dela, no presencial e no virtual, [...] Quando alunos e professores estão conectados, surgem novas oportunidades de interação, antes simplesmente impensáveis. (MORAN, 2003, p.1).

Estamos imersos em um mundo global, onde um fato expressivo, de qualquer natureza, que aconteça em um determinado ponto do espaço terrestre, é replicado, imediatamente, para todo o restante do planeta, tanto para o bem, mas em maior grau, para o mal. Vivemos uma pandemia de um vírus que surgiu numa cidade na Ásia e, rapidamente, atravessou fronteiras e espaços, atingindo mentes e medos. A circulação de pessoas parou compulsoriamente e estamos fazendo uma espécie de "isolamento social". As instituições de ensino não poderiam ficar de fora, estão parando por um período indeterminado, pois ainda não sabemos o que vai acontecer nos próximos dias. Nesse caso, surge uma questão: o que poderemos fazer?

Diante desse cenário conjuntural, essa sociedade está a vivenciar profundas mudanças de toda a ordem, nas práticas culturais, sociais, políticas e econômicas. Uma dessas mudanças se vincula à emergência de novas maneiras dominantes pelas quais experimentamos o tempo e o espaço (MILL, 2012). Desse modo, a resposta a questão anterior poderia ter uma solução, pois o tempo é instantâneo e o espaço existe em um piscar de olhos, ou de um toque no smatphone. A partir desse ponto, unindo a relação de tempo e espaço com a necessidade de se evitarem lugares com aglomeração, a educação a distância (EAD) é uma possibilidade de transmissão de conhecimento e desenvolvimento.

Desde o final do século passado assistimos à expansão da modalidade de EAD e suas relações com as Tecnologias Digitais da Informação e Comunicação (TDIC), como já vislumbrava Moran (1995, p.5), que estávamos começando a haver "um novo reencantamento pelas tecnologias porque participamos de uma interação muito mais intensa entre o real e o virtual". Em sua última publicação, o censo EAD.BR de 2018 (CENSO, 2018, p.7), ratifica que "nos cursos regulamentados totalmente a distancia, o número de matrículas aumentou de 1.320 .025 para 2.358.934", ou seja, um incremento de 78\%. A situação do número de matrículas na educação a distância aumentou, de 2017 para 2018, em mais de 1.500.000 de novos alunos, consolidando a modalidade como opção de formação.

$\mathrm{Na}$ literatura sobre o tema tecnologia é comum encontrarmos discussões que tratam dos seus "impactos", "como forma de tratar das implicações, consequências, resultados, transformações e resultados gerados, direta ou indiretamente, por ela" (ARAUJO; VILAÇA, 2016, p.19), o que não se enquadraria apenas em uma simples revolução tecnológica, o que 
este autor considera ser uma forma reducionista de se tratar de um tema tão relevante. Não se consideram os desmembramentos pertinentes ao campo da educação, em especial, quando se une interatividade e EAD, com diversos agentes interagindo de diversas maneiras, utilizando inúmeras ferramentas, com expectativas e objetivos bastante distintos (MATTAR, 2014).

Assim inicialmente exposto, chegamos, então, ao objeto do nosso estudo, o ambiente modular de aprendizagem dinâmica orientada a objetos, ou seja o Moodle ${ }^{1}$, uma plataforma de aprendizagem a distância, tendo por base um software livre, considerada eficiente e acessível. O Moodle permite criar um espaço destinado aos professores e alunos, que podem se comunicar e desenvolver uma EAD de qualidade. Essa plataforma é considerada um sistema consagrado, sendo uma das maiores bases de usuários em nível mundial.

O presente estudo, portanto, tem como objetivo principal apresentar as contribuições da utilização de aplicação do processo ensino-aprendizagem via EAD e das ferramentas utilizadas na plataforma Moodle no Curso de Direito Internacional dos Conflitos Armados (CDICA), da Escola Superior de Guerra (ESG), segundo a visão dos seus alunos. Este estudo se torna relevante, na medida em que as diversas contribuições expostas nas análises dos instrumentos de coleta de dados possam refletir em melhor qualificação dos futuros alunos e também mostrar as potencialidades da EAD em outros cursos com maior carga horária da instituição, em especial, numa época de quarentena.

A seguinte questão de pesquisa norteou este trabalho, a saber: Quais as principais contribuições na fase a distância dos discentes do CDICA-2019 para o seu processo ensino, aprendizagem e avaliação?

\section{Metodologia}

O cenário deste estudo é a Escola Superior de Guerra, o objeto de estudo, o CDICA, turma de 2019, um curso semipresencial. Esta pesquisa é de abrangência qualitativa. A metodologia empregada compreendeu a aplicação de dois questionários, com perguntas abertas aos sujeitos do estudo, 34 estagiários $^{2}$, entre militares e civis, de diversas áreas de formação profissional, apresentado na seção de análise das respostas coletadas. As coletas foram disponibilizadas por via de survey online, no Ambiente Virtual de Aprendizagem (AVA), ao final do curso, e abrangeram os campos da gestão e ensino.

De posse dos resultados dos questionários, efetuou-se uma análise do material gerado e, após essa fase, foi elaborada uma integração dos resultados encontrados nas respostas, a fim de extrair as inferências necessárias e importantes para se atingir o objetivo central, em resposta a questão de estudo, desvelando as contribuições mais significativas e as

\footnotetext{
${ }^{1}$ Modular Object-Oriented Dynamic Learning Environment

${ }^{2}$ Estagiários - como são denominados os alunos da ESG.
} 
apresentando aos gestores responsáveis pelo CDICA.

\section{Fundamentação teórica}

O objeto deste estudo é um curso semipresencial, em que conta com sua primeira fase a distância, pois recebe alunos de diversos setores da sociedade. Existe, portanto, a necessidade de entendermos que as tecnologias, em certa medida, influenciam o sistema de ensino-aprendizagem-avaliação, em qualquer nível de formação ou pós-formação, tanto em relação a posição dos docentes quanto dos seus alunos, estes que são "influenciados pela utilização ou falta de aplicação das metodologias de ensino que são desenvolvidas através dos recursos tecnológicos" (BARTELLE; BROILO NETO, 2019, p.282).

A Educação a Distância, em particular e segundo Honorato (2020), é entendida como um processo de ensino-aprendizagem no qual alunos e professores se encontram separados espacial e/ou temporalmente, e que tem uma relação fundante com a tecnologia. Mill (2012, p. 21), por sua vez, argumenta que ela seria uma modalidade de educação geralmente considerada uma forma alternativa e complementar para a formação do cidadão, "com ricas possibilidades pedagógicas e grande potencial para a democratização do conhecimento".

O processo em que a EAD é idealizada, em seu aspecto educacional, é "reconhecido como centrado no aluno e mediado pelas tecnologias da sociedade da informação, fato esse que leva à necessidade de se investigar como alunos e instrutores, com o uso das novas tecnologias, podem colaborar para gerar novos conhecimentos" (MUGNOL, 2009, p.339, grifo nosso). No caso em estudo foi dada voz aos participantes do CDICA a contribuírem para uma melhor utilização das ferramentas da plataforma Moodle.

Importante ressaltar que deve ser considerado a necessidade dos diferentes modelos de organização administrativo-pedagógica dos cursos a distância, estes que contemplam a flexibilização de tempo e espaço. As possiblidades tecnológicas em que as metodologias empregadas devem propiciar uma "maior interação e diálogo entre os atores do processo educacional, recursos e materiais didáticos em diferentes suportes, mediação pedagógica por intermédio das tecnologias" (GONTIJO; CARVALHO, 2018, p.3).

\section{A Escola Superior de Guerra e o CDICA}

A Escola Superior de Guerra é um instituto de altos estudos do Ministério da Defesa, criada em 20 de agosto de 1949. A busca pelo estímulo intelectual multidisciplinar fez com que, em 1951, além de militares dos estamentos superiores das três forças armadas, a instituição recebesse também a contribuição de civis do mais alto nível, dos diversos segmentos profissionais da sociedade. A sua missão é "Realizar estudos e pesquisas para compreender 
a realidade nacional e internacional, e preparar civis e militares para formular políticas e estratégias relativas ao desenvolvimento, à segurança e à defesa nacionais". Em suma: "O objetivo de todo o processo educacional da ESG visava à promoção da integração civil-militar, e o estabelecimento de uma rede de confiança entre os mesmos" (VIANNA, 2019, p.85).

A instituição tem sua sede na cidade do Rio de Janeiro, no bairro da Urca. O ano de 2011 representou um marco na história da ESG, com a expansão de suas atividades para a capital federal, materializada pela criação do Campus ESG-Brasília, reaproximando a Escola do centro político-administrativo do país. Além dos onze cursos realizados, tanto no Rio quanto em Brasília ${ }^{3}$, nas modalidades de extensão e pós lato sensu, encontramos o Programa de Pós-Graduação em Segurança Internacional e Defesa (PPGSID), mestrado stricto sensu, nas áreas de defesa, segurança e desenvolvimento estratégicos.

O Curso de Direito Internacional dos Conflitos Armados (CDICA) é um curso de extensão que se destina a preparar militares e civis para o exercício de funções de assessoramento de nível e de ensino. O foco são as questões relativas às leis dos conflitos armados, tanto no âmbito do Ministério da Defesa, quanto nos órgãos públicos ligados ao Direito Internacional dos Conflitos Armados (DICA). Além disso, visa-se à aplicação, respeito e garantia do cumprimento das normas internacionais de origem consuetudinária e capacitar para o assessoramento à alta direção e de funções ligadas ao ensino, diretamente relacionadas às normas do DICA.

A fim de atingir o objetivo geral do curso, a estrutura curricular do CDICA contempla cinco Unidades de Estudo (UE), com uma carga horária total de aproximadamente 130h, que articula e sistematiza os conteúdos abordados e integra conhecimentos das seguintes áreas: Direito Internacional; Relações Internacionais e o DICA; Instituições Internacionais e Segurança e Defesa; Justiça Militar da União e o DICA. A abordagem do curso considera o arcabouço jurídico nacional, bem como o de organismos internacionais. Para isso, os conteúdos ministrados se referem à aplicação, ao respeito e à garantia do cumprimento das convenções internacionais, sejam de origem convencional ou consuetudinária.

No ano da pesquisa, 2019, o curso foi desenvolvido, ao longo de cinco semanas, na modalidade semipresencial, cuja fase a distância ocorreu de 18 de fevereiro a 15 de março, excluindo-se o período do carnaval, com um efetivo planejado de quarenta e dois alunos. Contou com três Unidades de Estudo da Disciplina Noções básicas do Direito Internacional dos Conflitos Armados: "Origens, Histórico do DICA e Diferenças e convergências entre DH e DIH"; "Fundamentos, Tratados e Convenções do DICA e "Comportamento na Ação: o âmbito de aplicação do DICA" no AVA, o Moodle. A fase presencial ocorreu de 18 a 29 de março.

A abordagem metodológica desenvolvida pela Escola propicia aos alunos experiências

\footnotetext{
${ }^{3}$ Todos os cursos ofertados pela ESG são apresentados no sítio da instituição na internet. Disponível em: https://www.esg.br/cursos/cursos_regulares. Acesso em: 04 abr. 2020.
} 
práticas dos conteúdos estudados em diversos níveis de complexidade, configurando-se como um sistema de estudos, pesquisas e atividades, que requerem tanto desempenhos individuais como em grupo. Para tornar as atividades mais produtivas e dinâmicas, algumas técnicas de ensino são usadas, de modo a favorecer a participação, a troca de experiências e o desenvolvimento dos alunos.

\section{Análises e discussões}

As ferramentas utilizadas no AVA para dinamizar o curso escolhido foram: Midiateca, PDF simples, PDF interativo, café virtual, relação de sítios de pesquisa, fóruns mediados em todas as unidades de estudo, vídeo, vídeo-aula, tarefas individuais e em grupo, questionário de acompanhamento de aprendizagem, quiz virtual, emprego de Estudos de Casos, feedback dos estagiários e as avaliações de Gestão e de Ensino.

Ao final do acompanhamento da fase a distância, foram disponibilizados dois questionários, como já informado na metodologia. O primeiro de Gestão de Curso (GC) e outro de Gestão do Ensino (GE), ambos respondidos por 34 alunos, totalizando 80,95\% dos 42 alunos concluintes dessa fase, cuja análise dos dados será descrita adiante.

É importante caracterizar, em linhas gerais, o perfil dos estagiários da turma de 2019 , ou seja: dos 42 discentes, 27 eram militares das forças armadas, de diversos postos e quadros, e 15 eram civis ou militares estaduais e do Distrito Federal. No caso específico dos alunos civis e mostrando a importância do CDICA nos dias atuais, tínhamos assessora do Ministério da Justiça, advogado e procurador da Advocacia-Geral da União e juiz-auditor do Superior Tribunal Militar, entre outros.

Em estudo sobre a importância do feedback como fator a ser considerado na avaliação do discente e em sua formação a distância em cursos de pós-graduação, Passos (2020, p.5), afirma que "Os comentários devem trazer informações relativas à qualidade do trabalho com orientações do que fazer para melhorar". Entendemos, portanto, como importante selecionar as respostas mais relevantes encontradas nas pesquisas de GC e de GE, com base no objetivo destacado no início deste artigo.

\subsection{Instrumento de Avaliação da Gestão}

A Avaliação da Gestão da fase a distância teve como objetivo principal analisar o processo de desenvolvimento do curso, em nível operacional e subsidiário, investigando a efetividade e o impacto das unidades de estudo no cotidiano e na qualificação do trabalho dos estagiários, bem como a sua contribuição para a formação teórica e prática e a autonomia intelectual desse público-alvo. 
O questionário contou com 25 questões abertas. As primeiras procuraram compreender as dificuldades iniciais que o discente apresentou em relação ao processo de ensinoaprendizagem no espaço virtual, além das unidades de estudos e do guia de estudos a distância. Em sua grande maioria, acima de $92 \%$ dos respondentes, não encontraram dificuldades no trato inicial do curso. Nessa fase, é disponibilizado um vídeo tutorial] sobre o uso do sistema Moodle, que, para cerca de $12 \%$ dos estagiários, contribui de forma parcial para o entendimento do funcionamento da plataforma.

As questões seguintes trataram especificamente sobre o Ambiente Virtual de Aprendizagem (AVA), que, em ampla maioria, achou "dinâmico e atrativo". Em relação à facilidade de navegação, acessibilidade e agilidade, um dos respondentes não achou fácil, como transcrito em sua resposta: "Não foi tão simples de operar. Exige manobras de acesso que poderiam ser minimizadas ou suprimidas. Não é difícil, mas poderia ser mais prático". Essa sugestão foi participada aos responsáveis na Divisão de Educação a Distância (DED) da instituição para avaliação.

Continuando pelo AVA, os estagiários usaram, para o seu acesso, entre notebooks, desktops e celulares, cerca de $47,1 \%$, o que estivesse mais acessível no momento. Porém, $38,2 \%$ fez uso do seu notebook particular para seus acessos ao ambiente de trabalho, uma situação bem lógica e clara no trato das atividades que podem ser desenvolvidas assíncronas, a qualquer momento, em especial em suas residências.

A questão seguinte procurou verificar qual o período em que o estagiário mais acessou o ambiente virtual. Conforme mostrado no Gráfico 1, podemos verificar que o período noturno é o que apresenta maior número de respondentes, $70,6 \%$ do total. Infere-se que tal situação é ocasionada, em especial, devido ao curso em estudo ser semipresencial, quando os estagiários continuam trabalhando em suas organizações normalmente, tendo apenas o período noturno para acesso e realização de suas atividades acadêmicas. Um dos respondentes afirmou que "Embora tenha acessado muitas vezes pela manhã, o rendimento foi muito melhor no período noturno, principalmente, as participações nos Fóruns de Discussões."

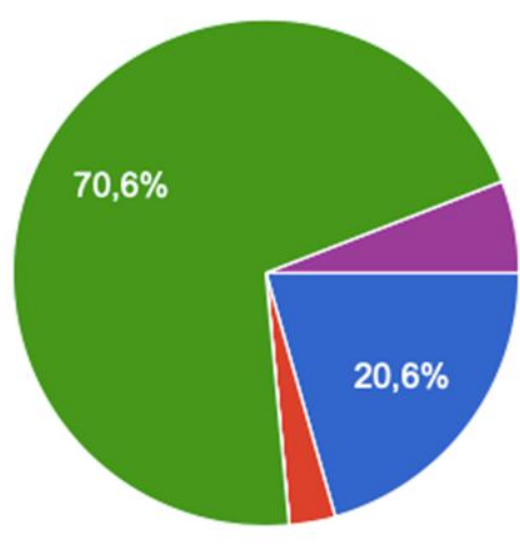

De manhã durante o expediente

De tarde no expediente

No horário de almoço

No período noturno

No final de semana

Gráfico 1 - Período de acesso ao AVA

Fonte: o autor. 
Uma questão causou diversas opiniões interessantes para a gestão do curso. Foi perguntado se o Mural utilizado como metodologia de apresentação dos estagiários foi importante. No Gráfico 2 a seguir exposto, podemos verificar que mais da metade achou "Legal e fácil de usar". Porém, um número significativo de respondente achou melhor que a apresentação nos fóruns, como deixou claro um dos discentes: "Sobre o mural, acredito ser um facilitador para a equipe de coordenação, mas na posição de aluno, não o utilizei". Mais de $10 \%$ acreditam que a apresentação poderia ocorrer posteriormente, na fase presencial do curso.

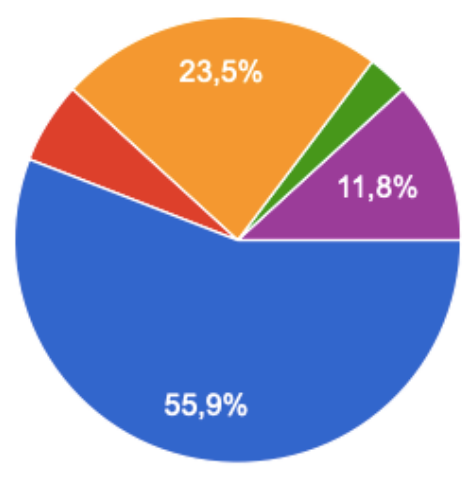

Legal e fácil de usar

Boa, mas não consegui usar

Prefiro me apresentar no Fórum

Acho a apresentação desnecessária

A apresentação poderia ocorrer posteriormente na fase presencial do curso

Não gosto de me apresentar

Gráfico 2 - Apresentação

Fonte: o autor.

Uma ferramenta utilizada na EAD é o fórum, onde são desenvolvidos ideias e temas baseados no conteúdo a ser estudado, com a exploração também das experiências dos discentes. Os fóruns são, portanto, um dos principais espaços proporcionadores de comunicação horizontal nos ambientes virtuais de aprendizagem. A proposta dos fóruns, no entanto, como bem destaca Titsworth (2017 apud BARROS; SANTOS; ROMERO, 2019, p.226) é, justamente, "resgatar o aspecto interpessoal da comunicação". O que ratificamos que é mais do que simplesmente entrada no AVA dos cursantes, mas importante espaços que proporcionem agregação social. O que é representado por $76,5 \%$ dos respondentes que gosta desse tipo de conversa assíncrona, porém, em sentido contrário, 23,5\% tem uma opinião contrária, pois não gostam de terem muitas mensagens para serem lidas, como deixou claro um dos estagiários: "Com o expediente e EAD é difícil seguir os fóruns. Ao término do expediente, com 133 mensagens no fórum, fica inviável".

Uma questão considerada relevante para os gestores do curso é avaliar se a interação entre discentes e docentes, nos fóruns de discussão, durante as unidades e ensino, foi satisfatória. A maioria respondeu que foi bem proveitosa para esclarecer dúvidas e enriquecer a matéria a ser estudada. Contudo, três estagiários se tornaram indiferentes, porque pouco interagiram no fórum. Uma colocação de um aluno surgiu como contribuição para os próximos 
Grupos de estudo a distância poderiam ser uma boa opção para criar uma interação maior, tipo grupos de até 5 componentes, por exemplo, previamente escolhidos, que teriam respectivos fóruns para uma interação entre eles e, assim, elaborarem um trabalho, se for o caso, exporem pontos de vista sobre um tema, e por aí vai.

Uma pergunta procurou levantar as preferências de leitura dos conteúdos das Unidades de Ensino (UE). Quase um empate, 47,1\% preferem que a disciplina de estudo venha por meio impresso, e 41,2\% não o preferem, bastou a leitura na tela do seu computador. Segundo um respondente, "o material na tela proporciona uma ótima mobilidade, mantendo a possibilidade de baixá-los para nossos desktops". Existe o aluno que acredita que a impressão, independente da possibilidade da racionalização do material a ser impresso, "depende do tamanho e objetivos a serem alcançados com a leitura. Dessa forma, posso imprimir o que desejar", com certa razão no trato dos estudos a serem desenvolvidos.

Uma pergunta procurou verificar o grau de satisfação e se suas expectativas foram atendidas em relação à vivência na fase a distância do CDICA. 94,1\% dos estagiários afirmaram que estão muito satisfeitos com o referido curso e o recomendariam em seu local de trabalho. Dois alunos sugeriram um aumento na carga horária da fase a distância, em cerca de uma semana. Um outro respondente acredita que alguns conteúdos poderiam ser explorados, como a "ocupação beligerante e seleção de alvos".

No curso de 2019, a ambientação dos alunos ocorreu em paralelo com as UE. Por isso mesmo, surgiu a questão sobre a impressão que os discentes tiveram dessa metodologia. Mais da metade dos respondentes sugerem que o material de ambientação venha antes do desenvolvimento do curso. Um percentual significativo, 20,6\%, gostaria que os conteúdos fossem liberados no início da fase a distância. Tal sugestão foi encaminhada ao diretor do CDICA. Um ponto ressaltado foi que a semana de ambientação é de fundamental importância para o bom desenvolvimento do curso, fase a distância.

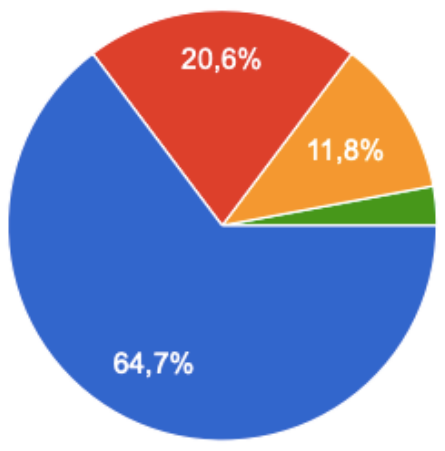

Penso que seria mais adequado liberar o material da ambientação primeiro e..

Gostaria que o conteúdo fosse disponibilizado todo no início juntamente com a a...

Acho indiferente

Não acho necessário haver um período específico para a ambientação (justifique)

Gráfico 3 - Ambientação dos alunos à Plataforma e ao CDICA

Fonte: $\mathrm{O}$ autor. 
A última questão a ser analisada deixou livre para que os estagiários apresentassem sugestões e contribuições para a gestão do curso, a fim de se obter um melhor planejamento na próxima edição do CDICA, em sua fase a distância. Como foram diversas contribuições, aproveitamos a oportunidade para elaborar uma costura textual das mais importantes, a saber:

Devido à quantidade de material a ser estudado, acho interessante liberar o acesso de cada unidade de ensino no final da semana que antecede o seu início. Simplificar o ambiente virtual, pois, às vezes, se torna confuso. Incluir exercícios de fixação e 'quizzes' sobre as unidades de ensino. A ambientação poderia ter mais atividades práticas. Poderia ser criada uma pasta virtual para que os estagiários colocassem arquivos pertinentes ao curso, para acesso para as turmas posteriores. Permitir que as tarefas de cada Unidade sejam concluídas no final da semana, pois cada um tem cargas de trabalho diferenciadas, além de possíveis imprevistos pessoais. Sugiro que o material dos fóruns seja disponibilizado anteriormente. Aumentar o período em uma semana. Acho que as discussões da fase em distância deveriam ocorrer com a participação de todos ao mesmo tempo, como se fosse um chat, em horário pré-estabelecido pelo tutor.

\subsection{Instrumento de Avaliação do Ensino}

A Avaliação do Ensino da fase a distância teve como objetivo entender se o conteúdo abordado, a carga horária, o material didático e o AVA estão configurados, de forma a potencializar a aprendizagem dos estagiários, no que tange a um ambiente de fácil entendimento, dinâmico para leitura e que possibilite a autonomia dos discentes em sua trilha de aprendizagem.

Esse questionário contou com 15 perguntas abertas, que foram elaboradas cada uma com três categorias distintas: (i) origens e histórico do DICA; (ii) fundamentos, tratados e convenções; e (iii) comportamento na ação, ou seja, de que forma o discente realizou a sua atividade acadêmica. A exemplo da análise anterior, não foram avaliadas todas as questões, apenas aquelas mais significativas para este estudo.

A questão inicial procurou verificar se a profundidade dos conteúdos abordados foi adequada durante o desenvolvimento do curso. Um aluno, que se percebe ser de origem civil, comentou "porque venho de uma área do Direito muito distinta e pude assimilar os conteúdos, estimulado a pesquisar e buscar nivelar meus conhecimentos aos demais estagiários". Um dos discentes criticou a parte de fundamentos, tratados e convenções, pois acredita que "muitos aspectos particulares das convenções deixaram de ser tratados, [...] por falta de tempo na fase presencial". Situação apresentada ao diretor do CDICA.

Uma questão procurou abordar se a modalidade de ensino a distância foi apropriada para as UE. Dois estagiários expuseram suas observações, tanto no aspecto negativo, como "Seria interessante que o período presencial tivesse uma carga horária maior, de forma que 
as unidades do EAD fossem também abordadas na primeira semana presencial, podendo ser a título de revisão"; ou positivo, a saber,

[...] perfeitamente! Essa modalidade de ensino exige uma dose de comprometimento e regularidade de acessos para que se atinjam os objetivos; aqueles que têm tempo disponível conseguem assimilar e aprofundar os estudos mais do que outros, mesmo pela afinidade ao assunto abordado, mas o trilho está posto para todos que, a qualquer momento, quiserem colocar a locomotiva do conhecimento em frente.

Uma situação sempre vivenciada durante o desenvolvimento de um curso, quer na modalidade a distância ou mesmo na fase presencial, é se a carga horária alocada as unidades, no nosso estudo seria por via da $E A D$, foi satisfatória. Podemos verificar que, devido às diversas formações profissionais, tivemos alunos com dificuldade, sugerindo mais tempo; outros acreditam que os assuntos eram profundos, e o tempo disponibilizado foi adequado. Uma constatação recorrente foi a sugestão para ampliar em mais uma semana o período a distância, e, por conseguinte, o curso, o que pode ser verificado no Gráfico 4 a seguir, pela insuficiência nas três categorias.

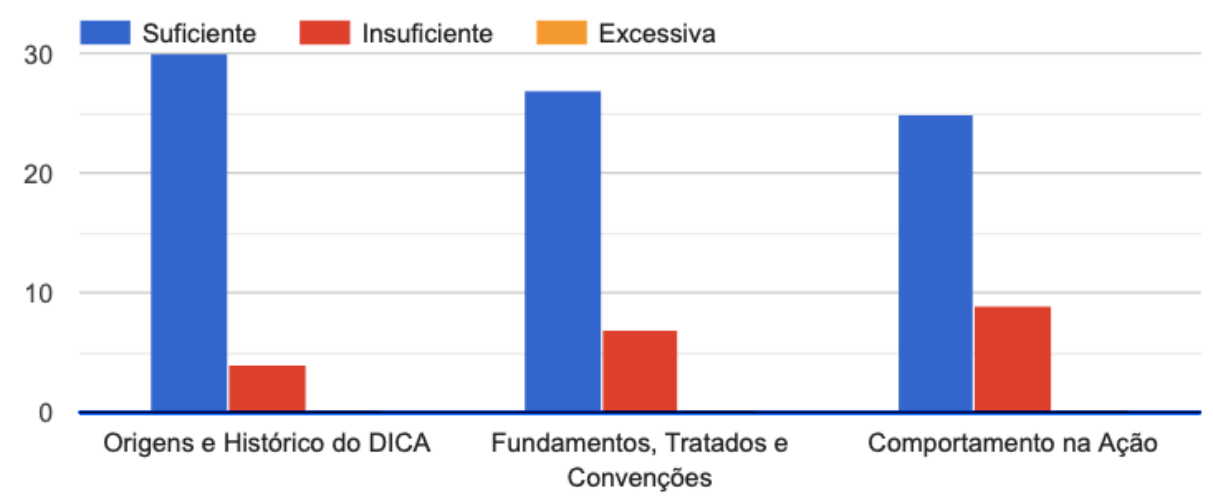

Gráfico 4 - Carga horária na fase a distância

Fonte: $\mathrm{O}$ autor.

A questão que se seguiu procurou avaliar se a quantidades de atividades propostas aos estagiários foram adequadas, insuficientes ou excessivas. Este estudo é de abrangência qualitativa, não cabem generalizações, mas um respondente a achou excessiva e ainda comentou: "O ideal seria somente uma atividade por unidade de ensino, particularmente, porque a maior parte dos estagiários mantém a carga de trabalho normal durante o EAD". Situação que não tem muito a analisar, correta a colocação do discente, porém, a sugestão de uma atividade por UE foi apresentada como contribuição para o encarregado do CDICA para sua deliberação.

Como os sujeitos deste estudo são militares das forças armadas, forças auxiliares e de segurança e servidores civis, um óbice foi exposto por um aluno da Força Aérea, em relação à pergunta que procurou avaliar se os recursos audiovisuais e multimídia utilizados pelos 
docentes foram adequados ao desenvolvimento do curso. Esse estagiário respondeu que "A plataforma Youtube é bloqueada na FAB e, como sugestão, falaria para as aulas serem disponibilizadas na própria plataforma". Situação apresentada aos gestores do curso.

Em relação às questões seguintes, avaliadas como 100\% satisfatórias, apresentaremos uma síntese: (i) o AVA está organizado de forma a proporcionar a consolidação da aprendizagem mais interativa; (ii) procedimentos didáticos demonstrados pelos docentes; (iii) docentes assumiram uma atitude de facilitadores da aprendizagem; (iv) a sequência dos arquivos disponibilizados contribuiu para o entendimento e o desenvolvimento das disciplinas; e (v) as atividades propostas pelos docentes foram importantes para exercitar o conteúdo aprendido. Tais constatações, vão ao encontro que Sartório, Jung e Silva (2019, p.94), em seu estudo sobre a qualidade proporcionada aos docentes de pós-graduação na EAD, que "a estrutura, qualidade e material que o professor necessita para ministrar sua aula e acesso à tecnologia, permitindo uma aula mais interativa".

Em certa medida, os alunos não gostam dos trabalhos em grupo. Por isso mesmo, a questão procurou sentir o que prefere o aluno - no caso em estudo, pessoas de diversas áreas de formação superior em um curso de extensão. Como mostrado no Gráfico 5 , podemos verificar que a preferência é por trabalhos individuais, $82,5 \%$, como ratificou um dos estagiários:

A dificuldade na realização de tarefas em grupo na fase a distância é muito grande, uma vez que, na grande maioria, os estagiários permanecem desenvolvendo suas atividades nos órgãos de origem e os horários de acesso são muito distintos, o que traz uma disparidade de envolvimento na ação de treinamento, assim como se observa nos comentários individuais, em que alguns conseguem se envolver profundamente e outros, superficialmente.

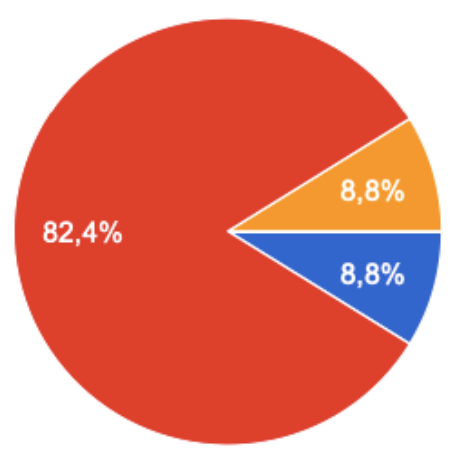

Em grupo

Individual

Indiferente

Não acho necessário realizar atividades

Gráfico 5 - Preferência por trabalhos em grupo ou individual

Fonte: $\mathrm{O}$ autor.

A exemplo do questionário anterior, a última questão foi livre, procurou-se dar voz ao estagiário em relação a comentários, críticas ou sugestões para melhorar a qualidade da próxima edição do CDICA, na sua fase a distância. Como foram diversas respostas, apresentamos as principais em uma costura textual, a saber: 
Algumas referências apresentadas nos fóruns foram relevantes para o aprendizado. A critério dos instrutores, sugiro avaliar e incluir as mais pertinentes na midiateca das próximas turmas, como leitura complementar. Substituir as perguntas individuais por fóruns, a fim de permitir o acesso dos estagiários a todas as opiniões e material disponibilizado. Os debates são fundamentais para construir e consolidar o conhecimento. Os temas foram instigantes, ricos em conteúdos auxiliares, facilitando a pesquisa. O material didático, recursos disponibilizados, tutoria e mediação dos professores me surpreenderam bastante positivamente. Manter todos os fóruns de discussão abertos até às 23h55. A noite é sempre melhor para se concentrar, sem as interrupções no trabalho ou mesmo em casa. Acredito que o curso chegou ao seu 'estado da arte'. A plataforma é bem amigável, e o conteúdo, muito bem organizado e de fácil acesso. Como a fase a distância exige disponibilidade de tempo, que deve ser somado às atividades profissionais rotineiras, e autodisciplina, seria interessante que os estagiários tivessem mais tempo para concluir as atividades e aprofundar os estudos. Acho que um número maior de estudos de casos ajudaria no aprendizado. Acharia interessante um módulo que aborde superficialmente o Direito Penal Internacional e a responsabilidade do Comando, pois acho importante ter um mínimo de conhecimento sobre esse ramo do Direito, antes da aula presencial.

\section{Considerações Finais}

A epígrafe inicial deste artigo do professor José Manuel Moran deixa claro que tanto o ensinar como o aprender não mais se limitam a quatro paredes, ainda mais em um mundo tecnológico e globalizado. O curso em estudo, em sua fase a distância, contemplou diversos conteúdos nas áreas de Direito Internacional, de Relações Internacionais, de estrutura e funcionamento dos principais organismos internacionais, de Segurança e Defesa, de fundamentos do DICA, dos Direitos Humanos (DH) e do Direito Internacional Humanitário (DIH), o que assegurou conhecimento atualizado dos principais tratados e convenções, bem como dos procedimentos gerais de comportamento em uma ação de conflito armado.

Ao utilizar a plataforma digital para a aprendizagem, o CDICA mostrou que o ensino a distância não é efêmero na sociedade da informação. Pelo contrário, essa tendência se efetiva dia após dia, por meio de uma quantidade maior de usuários, prova de que tal modalidade de educação atende às necessidades atuais impostas pelo mercado de trabalho e por restrições conjunturais de idas e vindas. Nesse sentido e de uma maneira mais ampla, uma série de estudos podem ser realizados com vista a implementar o ensino a distância nos demais cursos da ESG, de modo semipresencial, bem como a apresentar suporte aos cursos presenciais e a criar cursos integralmente a distância.

Depois dos aspectos levantados, entende-se que para o curso ser bem-sucedido, ele deve contar com uma equipe capacitada e motivada ao sucesso conjunto. Desse modo, a fase a distância do CDICA 2019 atingiu os objetivos estabelecidos para o curso e superou as expectativas, em razão do comprometimento e da interação dos participantes no envolvimento da proposta do curso, em testar e aprender juntos, e, muito importante, apresentar propostas e sugestões para os futuros cursos. 
Os resultados obtidos nas avaliações realizadas comprovaram que as expectativas dos alunos, na fase a distância, foram atendidas satisfatoriamente, e os estudos foram essenciais para subsidiar os desdobramentos que foram aprofundados na fase presencial posterior. Ao final, os seguintes pontos levantados foram apresentados aos coordenadores do CDICA na instituição, como forma de contribuição dos discentes da turma de 2019, a saber: (i) fórum de discussão aberto em ambas as fases do curso; (ii) aplicação e ampliação dos estudos de casos; (iii) criação de uma pasta virtual com todo o material do curso e os estudos realizados pelos estagiários; (iv) possibilidade de especialização futura para os egressos do curso: (v) Plano de Ensino e Aprendizagem aperfeiçoados; e (vi) pré-teste de avaliação dos conhecimentos prévios dos estagiários.

\section{Referências}

ARAÚJO, E. V. F. de; VILAÇA, M. L. C. Sociedade conectada: Tecnologia, cidadania e infoinclusão. In: ARAÚJO, E. V. F. de; VILAÇA, M. L. C. (Orgs.). Tecnologia, Sociedade e Educação na Era Digital. Duque de Caxias: Unigranrio, 2016. p.17-40. E-book. ISBN : 978-8588943-69-8.

BARROS, D. M. V.; SANTOS, V. M. dos; ROMERO, C. S. Estratégias para o trabalho colaborativo: revisitando o uso de fóruns on-line na educação a distância. Revista Diálogo Educacional, Curitiba, v.19, n.60, p.221-245, 2019. Disponível em: http://dx.doi.org/10.7213/1981-416X.19.060.DS10. Acesso em: 05 abr. 2020.

BARTELLE, L. B.; BROILO NETO, G. A inserção das tecnologias nas metodologias de ensino. Horizontes - Revista de Educação, Dourados-MS, v. 7, n. 13, p. 280-297, jan./jun. 2019. Faculdade de Educação (FAED) da Universidade Federal da Grande Dourados (UFGD). Disponível em: http://ojs.ufgd.edu.br/index.php/horizontes/article/view/9717/5233. Acesso em: 04 jun. 2020.

CENSO EAD.BR: relatório analítico da aprendizagem a distância no Brasil 2018. [livro eletrônico]/[organização] ABED - Associação Brasileira de Educação a Distância. Curitiba: InterSaberes, 2019. ISBN 978-85-227-0135-3. Disponível em: http://www.abed.org.br/site/pt/midiateca/censo ead/. Acesso em: 04 abr. 2020.

GONTIJO, E. J. de A.; CARVALHO, R. M. A. de. Educação hibrida: desafios apontados pela avaliação discente. In: CONGRESSO INTERNACIONAL DE EDUCAÇÃO E TECNOLOGIA E ENCONTRO DE PESQUISADORES EM EDUCAÇÃO A DISTÂNCIA [CIET: EnPED: 2018]. Anais eletrônicos... Universidade Federal de São Carlos, São Carlos, 26 de junho a 13 de julho de 2018.2 Disponível em: https://cietenped.ufscar.br/submissao/index.php/2018/article/view/169. Acesso em: 04 jun. 2020.

HONORATO, H. G. O tutor na EaD: quem é esse sujeito? SILVA, D. da; JORGE, W. J. (Orgs.). Educação a distância [recurso eletrônico]: novas possibilidades e desafios para o ensino. Maringá, PR: Uniedsul, 2020. p.255-266.

MATTAR, J. Interatividade e aprendizagem. In: LITTO, F. M.; FORMIGA, M. M. M. (Orgs.). Educação a distância: o estado da arte. 8. reimp. São Paulo: Pearson Education do Brasil, 
2014. p.112-120.

MILL, D. Docência virtual: uma visão crítica. Campinas: Papirus, 2012. (Coleção Papirus Educação).

MORAN, J. M. Novas tecnologias e o re-encantamento do mundo. Revista Tecnologia Educacional. Rio de Janeiro, v. 23, n.126, p.24-26, set./out. 1995. Disponível em: http://www.eca.usp.br/prof/moran/novtec.htm. Acesso em: 04 jun. 2020.

MORAN, J. M. Educação inovadora presencial e a distância. 2003. Disponível em: http://www.eca.usp.br/prof/moran. Acesso em: 04 jun. 2020.

MUGNOL, M. A Educação a Distância no Brasil: conceitos e fundamentos. Rev. Diálogo Educ., Curitiba, v. 9, n. 27, p. 335-349, maio/ago. 2009. Disponível em: https://periodicos.pucpr.br/index.php/dialogoeducacional/article/view/3589. Acesso em: 04 jun. 2020.

PASSOS, M. L. S. Feedback como Parte Integrante da Avaliação Formativa em um Curso de Pós-graduação a Distância: Concepções da Equipe Multidisciplinar. Revista Brasileira de Aprendizagem Aberta e a Distância, v.19, n.1, fluxo contínuo, 2020. Disponível em: http://seer.abed.net.br/index.php/RBAAD. Acesso em: 04 abr. 2020.

SARTÓRIO, M.; JUNG, H. S.; SILVA, L. de Q. da. Qualidade assistencial aos professores de pós-graduação na EaD. Revista EDaPECI, São Cristovão, SE, v.19. n. 2, p. 85-95 maio/ago. 2019. Disponível em: DOI: http://dx.doi.org/10.29276/redapeci.2019.19.211152.85-95. Acesso em: 05 abr. 2020.

VIANNA, G. de S. O cruzeiro e a corrente: a Escola Superior de Guerra como máquina de hegemonia (1949-1961). Revista da Escola Superior de Guerra, [S.I.], Rio de Janeiro, v. 34, n. 70 , p. 72-95, abr./jun. 2019. ISSN 2675-2174. Disponível em: <https://revista.esg.br/index.php/revistadaesg/article/view/1060>. Acesso em: 05 abr. 2020. 